\title{
PLACE OF TRANEXAMIC ACID IN MODERN MEDICINE
}

\author{
Mahdi Al-Jeabory ${ }^{1,2}{ }^{\infty}$, Jaroslaw Pecold ${ }^{3}$, Aleksandra Gasecka ${ }^{4}$, \\ Lukasz Szarpak ${ }^{5,6} \odot$, Wladyslaw Gawel ${ }^{7} \oplus$, Nataliia Litvinova ${ }^{8} \odot$ \\ ${ }^{1}$ Institute of Outcomes Research, Polonia University, Czestochowa, Poland \\ ${ }^{2}$ Polish Society of Disaster Medicine, Warsaw, Poland \\ ${ }^{3}$ Department of Trauma and Orthopedic Surgery, Ruda Slaska City Hospital, Ruda Slaska, Poland \\ ${ }^{4} 1$ st Chair and Department of Cardiology, Medical University of Warsaw, Poland \\ ${ }^{5}$ Maria Sklodowska-Curie Medical Academy in Warsaw, Poland \\ ${ }^{6}$ Maria Sklodowska-Curie Bialystok Oncology Center, Bialystok, Poland \\ ${ }^{7}$ Department of Surgery, The Silesian Hospital in Opava, Czech Republic \\ ${ }^{8}$ European Medical School, International European University, Kiev, Ukraine
}

\begin{abstract}
Massive bleedings, both internal and external, are among the leading causes of preventable deaths. The research for the appropriate treatment focuses not only on looking for the new drugs but also relies on finding the new indications for the drugs already known in the pharmacotherapy of different disease. However, such an approach requires new protocols in order to be effective. One of the substances in question is tranexamic acid, which uses due to its antifibrinolytic effect is raising both in prehospital and hospital settings.
\end{abstract}

KEY WORDS: tranexamic acid, TXA, trauma, bleeding, hemorrhage

Disaster Emerg Med J 2021; 6(2): 85-89

\section{INTRODUCTION}

Tranexamic acid (TXA) is a low molecular antifibrinolytic drug [1] that has been used for many years to control hemorrhage in patients with hemophilia and other disorders involving coagulation system. The particular interest in TXA use was initially found by its ability to control massive hemorrhages in the prehospital setting, especially in the tactical environment, due to a statistically significant reduction of risk of death, when used in the early stage of pharmacotherapy [2-4]. The search for the safe and effective drug, which may be used in the prehospital control of hemorrhage is related to the epidemiology of injuries and its impact on the mortality of the overall population. According to the data provided by the WHO on their website, injuries are responsible for up to $10 \%$ of global deaths annually. In 2003, they caused the death of 5 million people worldwide, mainly as a result of traffic accidents, and required hundreds of millions of medical services provided in emergency departments $[5,6]$. In 2019, road accidents accounted for the 7th cause of death in countries with low financial status and 10th in countries with a slightly higher status; in highly developed countries, deaths resulting from traffic accidents were outside the top ten causes of mortality $[7,8]$. However, regardless of the socio-economical status of the country, the trauma and associated bleeding is the leading cause of mortality and morbidity worldwide $[9,10]$. Therefore, we have decided to dig further into the subject of the usage of TXA and perform this literature review regarding the usage, advantages and disadvantages of TXA application in the real-life setting.

\section{Mechanism of action and the usage of TXA}

In order to understand and fully appreciate the TXA mechanism of action, one must realize that coagu- 
lation is not just a process of blood clot formation but also it is dissolving by the plasmin [11, 12]. This delicate balance is maintained by various mechanisms. However, in case of major trauma the coagulopathy ensues resulting in uncontrollable bleeding [13]. Patients in this state require more blood transfusions, longer hospitalization time and overall present higher mortality [13]. This state, however, is not just the result of blood loss alone, patients who undergo major trauma with severe blood loss develop coagulopathy also in the mechanism of hemodilution, hyperthermy, acidosis and finally due to the consumption of blood factors they develop disseminated intravascular coagulation [14]. Therefore, a research for the new drugs that would ideally stop or at least slow down this cascade commenced. This result in the production of TXA which is the synthetic amino acid that inhibits the plasma plasminogen activators and to some extent the tissue plasminogen activators, which in turns blocks the conversion of plasminogen into plasmin. Additionally, TXA presents some activity regarding direct plasmin inhibition $[1,15]$. The laboratory findings in the studies show reduced $\mathrm{D}$-dimer concentration, a product of cross-linked fibrin breakdown [16].

All of these biochemical properties of TXA allow for an inhibition of fibrinolysis, which is the process of dissolving the blood clot by plasmin, and therefore it maintains the hemostasis. Additionally, TXA has been proven to increase thrombus formation [15]. All of these mechanisms of action resulted in their widespread use in different fields of medicine. The indications for drug administration include primary and generalized fibrinolysis, bleeding associated with the use of fibrinolytic drugs, vaginal bleeding, e.g. in the course of heavy menstruation, bleeding from the gastrointestinal tract and the urinary tract of various etiologies. These drugs are also used to limit the blood loss resulting from otolaryngological, cardiosurgical, gynecological or abdominal surgery [17-19].

Despite many clinical studies, publications and meta-analyzes, no clear consensus regarding the use of TXA in trauma patients has been established [19]. There are studies that prove a significant reduction in mortality in patients with hemorrhages when the TXA was administered within 3 hours following the injury [20]. A statistically significant reduction in the progression of intracranial bleeding and a statistically insignificant improvement in the results in patients with craniocerebral trauma was proven [21]. Studies also indicate a reduction in overall blood loss and a number of a blood transfusion given in patients undergoing elective procedures: knee and hip arthroplasty and the shoulder-scapular joint $[22,23]$.

\section{Contraindications for TXA application}

The contraindications for the TXA application include mainly the diseases that lead to hypercoagulation, mainly history of venous thrombosis and pulmonary embolism, arterial thrombosis (angina pectoris), history of myocardial infarction and disseminated intravascular coagulation. Additionally, severe renal insufficiency and seizures are also among contraindications for TXA application. As with any drug, the history of intolerance or allergy to the TXA automatically declines the use of this drug. TXA should be avoided in pregnant and lactating women, as well as children below 1 year of age

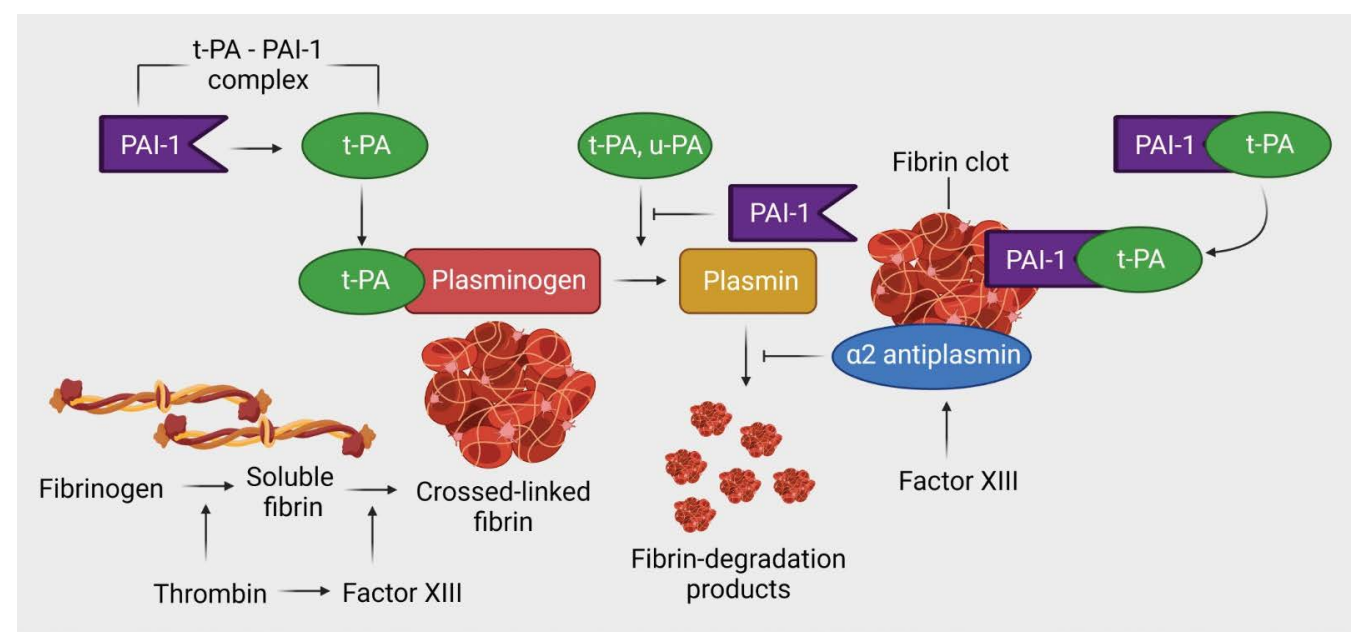

FIGURE 1. Management of tranexamic acid (created with BioRender.com, licensed version) 
$[24,25]$. One has to be careful when administering TXA in patients who are at risk of slower drug elimination e.g. with renal inefficiency, cardiac or neurological diseases $[26,27]$. As TXA has proven to bind to GABAa receptors, thus blocking GABA-mediated inhibition in the central nervous system, these patients are at risk of developing seizures following TXA administration [28]. This complication may be managed by administering the anesthetic agents that would modulate the receptors blocked by TXA, e.g. propofol [29].

\section{TXA as drugs in Poland}

In Poland, the drug is available as EXACYL (Sanofi) in three forms oral tablets at a dose of $500 \mathrm{mg}$, solution for injection at a dose of $100 \mathrm{mg} / \mathrm{ml}$ and the solution for digestion with the concentration of $100 \mathrm{mg} / \mathrm{ml}$. When administered orally, it is absorbed quickly and the maximum concentration in the blood serum is reached after $2-3$ hours, while after 6 hours following the administration, the drug is not detected. The half-life of the drug administered in the oral form is 1 hour, while in the intravenous form it is 3 hours. The drug is eliminated mainly by kidneys in urine $(90 \%)$ unchanged within 12 hours after administration [35-37].

\section{Tranexamic acid dosing}

The off-label dosing of tranexamic acid has not been established. It is recommended to administer the TXA in a dose of $1 \mathrm{~g}$ diluted in $100 \mathrm{ml}$ of $0.9 \%$ $\mathrm{NaCl}$ within 10 minutes for up to 3 hours from the hemorrhagic injury and to re-administer the drug in a dose of $1 \mathrm{~g}$ for the next 8 hours as an intravenous infusion [30-34]. One should pay attention to the factors that may impair the blood clot formation e.g., drop in body temperature or disturbance in the overall fluid status [30]. No consensus regarding the dosing of TXA in patients with craniocerebral injuries or undergoing elective orthopedic surgery has been established [23, 35, 36]. The advantages of using TXA in pre-hospital management have been proven during randomized clinical trials $\mathrm{CRASH}-2$ and CRASH-3, which were carried out by the London School of Hygiene and Tropical Medicine. Dosage and application regimens may be found in the recommendations of various groups, such as Task Force for Advanced Bleeding Care in Trauma, International Trauma Life Support, Tactical Combat Casualty Care or The Committee for Tactical Emergency Casualty Care (C-TECC) [37, 38].

\section{CONCLUSION}

New studies constantly show up in the medical literature regarding the possible label use of TXA. These studies report that TXA administration in the emergency settings, both in pre and hospital environment, significantly increases the survival rate of the patients suffering from severe hemorrhagic injuries. Additionally, this relatively cheap and easily available drug may increase the safety of the patients who undergo major elective surgery, due to the reduction of required blood transfusions. Due to the lack of unified dosing protocols and ongoing discussions regarding safety and indications for the TXA administration further analysis of literature is required to establish the consensus on TXA therapy.

\section{REFERENCES}

1. Hunt BJ. The current place of tranexamic acid in the management of bleeding. Anaesthesia. 2015; 70 Suppl 1: 50-3, e18, doi: 10.1111/ anae.12910, indexed in Pubmed: 25440395.

2. Moore EE, Moore HB, Kornblith $L Z$, et al. Subcommittees on Fibrinolysis, Disseminated Intravascular Coagulation, and Perioperative and Critical Care Thrombosis and Hemostasis, TACTIC Investigators. Trauma-Induced Coagulopathy: An Institution's 35 Year Perspective on Practice and Research. Scand J Surg. 2014; 103(2): 89-103, doi: 10.1177/1457496914531927, indexed in Pubmed: 24786172.

3. Stansfield R, Morris D, Jesulola E. The Use of Tranexamic Acid (TXA) for the Management of Hemorrhage in Trauma Patients in the Prehospital Environment: Literature Review and Descriptive Analysis of Principal Themes. Shock. 2020; 53(3): 277-283, doi: 10.1097/ SHK.0000000000001389, indexed in Pubmed: 32044848.

4. Al-Jeabory M, Szarpak L, Attila K, et al. Efficacy and Safety of Tranexamic Acid in Emergency Trauma: A Systematic Review and Meta-Analysis. J Clin Med. 2021; 10(5), doi: 10.3390/jcm10051030, indexed in Pubmed: 33802254.

5. Matthay ZA, Hellmann ZJ, Callcut RA, et al. Outcomes after ultramassive transfusion in the modern era: An Eastern Association for the Surgery of Trauma multicenter study. J Trauma Acute Care Surg. 2021; 91(1): 24-33, doi: 10.1097/TA.0000000000003121, indexed in Pubmed: 34144557.

6. Zhao WJ, Liu GE, Tian Y, et al. What's new in trauma 2020. Chin J Traumatol. 2021; 24(2): 63-68, doi: 10.1016/j.cjtee.2021.02.001, indexed in Pubmed: 33612396.

7. Khanna VA, Chidambaram S, Goh EnL. Prehospital Advanced Life Support for Out-of-Hospital Cardiac Arrest in Blunt Trauma Patients. JAMA Surg. 2019; 154(1): 95-96, doi: 10.1001/jamasurg.2018.4291, indexed in Pubmed: 30422252.

8. Brambrink AM, Koerner IP. Prehospital advanced trauma life support: how should we manage the airway, and who should do it? Crit Care. 2004; 8(1): 3-5, doi: 10.1186/cc2420, indexed in Pubmed: 14975036 
9. Johnson WD, Griswold DP. Traumatic brain injury: a global challenge. Lancet Neurol. 2017; 16(12): 949-950, doi: 10.1016/S14744422(17)30362-9, indexed in Pubmed: 29122521.

10. LaPelusa A, Dave HD. Physiology, Hemostasis. Treasure Island (FL): StatPearls Publishing. ; 2021.

11. Martini WZ. Coagulation complications following trauma. Mil Med Res. 2016; 3: 35, doi: 10.1186/s40779-016-0105-2, indexed in Pubmed: 27895932.

12. WOLFSON U. BLOOD LOSS IN TRAUMA. Ann R Coll Surg Engl. 1963; 33: 158-164, indexed in Pubmed: 14048752.

13. Neeki MM, Dong F, Toy J, et al. Efficacy and Safety of Tranexamic Acid in Prehospital Traumatic Hemorrhagic Shock: Outcomes of the CalPAT Study. West J Emerg Med. 2017; 18(4): 673-683, doi: 10.5811/ westjem.2017.2.32044, indexed in Pubmed: 28611888.

14. Frith D, Goslings JC, Gaarder C, et al. Definition and drivers of acute traumatic coagulopathy: clinical and experimental investigations. J Thromb Haemost. 2010; 8(9): 1919-1925, doi: 10.1111/j.15387836.2010.03945.x, indexed in Pubmed: 20553376.

15. McCormack PL. Tranexamic acid: a review of its use in the treatment of hyperfibrinolysis. Drugs. 2012; 72(5): 585-617, doi: 10.2165/11209070-000000000-00000, indexed in Pubmed: 22397329.

16. Dirkmann D, Görlinger K, Gisbertz C, et al. Factor XIII and tranexamic acid but not recombinant factor VIla attenuate tissue plasminogen activator-induced hyperfibrinolysis in human whole blood. Anesth Analg. 2012; 114(6): 1182-1188, doi: 10.1213/ANE.0b013e31823b6683, indexed in Pubmed: 22104068.

17. Cho MJ, Rohrich RJ, Rohrich RJ, et al. The Role of Tranexamic Acid in Plastic Surgery: Review and Technical Considerations. Plast Reconstr Surg. 2018; 141(2): 507-515, doi: 10.1097/PRS.0000000000003926, indexed in Pubmed: 28938364.

18. Myles PS, Smith JA, Kasza J, et al. ATACAS investigators and the ANZCA Clinical Trials Network, ATACAS investigators and the ANZCA Clinical Trials Network, ATACAS Investigators of the ANZCA Clinical Trials Network, ATACAS Investigators of the ANZCA Clinical Trials Network. Stopping vs. Continuing Aspirin before Coronary Artery Surgery. N Engl J Med. 2016; 374(8): 728-737, doi: 10.1056/NEJMoa1507688, indexed in Pubmed: 26933848.

19. Monaco F, Nardelli $P$, Pasin L, et al. Tranexamic acid in open aortic aneurysm surgery: a randomised clinical trial. $\mathrm{Br} J$ Anaesth. 2020; 124(1): 35-43, doi: 10.1016/j.bja.2019.08.028, indexed in Pubmed: 31607387.

20. Ker K, Roberts I, Shakur H, et al. CRASH-2 Trial collaborators, CRASH-2 Trial collaborators. Antifibrinolytic drugs for acute traumatic injury. Cochrane Database Syst Rev. 2011; 12(1): CD004896, doi: 10.1002/14651858.CD004896.pub3, indexed in Pubmed: 21249666.

21. Zehtabchi S, Abdel Baki SG, Falzon L, et al. Tranexamic acid for traumatic brain injury: a systematic review and meta-analysis. Am J Emerg Med. 2014; 32(12): 1503-1509, doi: 10.1016/j.ajem.2014.09.023, indexed in Pubmed: 25447601.

22. Fillingham YA, Ramkumar DB, Jevsevar DS, et al. The Efficacy of Tranexamic Acid in Total Knee Arthroplasty: A Network Meta-Anal- ysis. J Arthroplasty. 2018; 33(10): 3090-3098.e1, doi: 10.1016/j. arth.2018.04.043, indexed in Pubmed: 29805106.

23. Kirsch JM, Bedi A, Horner N, et al. Tranexamic Acid in Shoulder Arthroplasty: A Systematic Review and Meta-Analysis. JBJS Rev. 2017; 5(9): e3, doi: 10.2106/JBJS.RVW.17.00021, indexed in Pubmed: 28902659.

24. Ahmadzia HK, Luban NLC, Li S, et al. Optimal use of intravenous tranexamic acid for hemorrhage prevention in pregnant women. Am J Obstet Gynecol. 2020 [Epub ahead of print], doi: 10.1016/j. ajog.2020.11.035, indexed in Pubmed: 33248975.

25. Franchini M, Mengoli $C$, Cruciani $M$, et al. Safety and efficacy of tranexamic acid for prevention of obstetric haemorrhage: an updated systematic review and meta-analysis. Blood Transfus. 2018; 16(4): 329-337, doi: 10.2450/2018.0026-18, indexed in Pubmed: 29757132.

26. Bhat A, Bhowmik DM, Vibha D, et al. Tranexamic acid overdosage-induced generalized seizure in renal failure. Saudi J Kidney Dis Transpl. 2014; 25(1): 130-132, doi: 10.4103/1319-2442.124529, indexed in Pubmed: 24434397.

27. Takagi $H$, Ando $T$, Umemoto $T$, et al. All-Literature Investigation of Cardiovascular Evidence (ALICE) group. Seizures associated with tranexamic acid for cardiac surgery: a meta-analysis of randomized and non-randomized studies. J Cardiovasc Surg (Torino). 2017; 58(4): 633-641, doi: 10.23736/50021-9509.17.09877-9, indexed in Pubmed: 28263046.

28. Manji RA, Grocott HP, Leake J, et al. Seizures following cardiac surgery: the impact of tranexamic acid and other risk factors. Can J Anaesth. 2012; 59(1): 6-13, doi: 10.1007/s12630-011-9618-z, indexed in Pubmed: 22065333.

29. Hales TG, Lambert JJ. The actions of propofol on inhibitory amino acid receptors of bovine adrenomedullary chromaffin cells and rodent central neurones. Br J Pharmacol. 1991; 104(3): 619-628, doi: 10.1111/j.1476-5381.1991.tb12479.x, indexed in Pubmed: 1665745.

30. Donovan RL, Varma JR, Whitehouse MR, et al. Tranexamic acid use to decrease blood loss in primary shoulder and elbow replacement: A systematic review and meta-analysis. J Orthop. 2021; 24: 239-247, doi: 10.1016/j.jor.2021.03.003, indexed in Pubmed: 33854291.

31. Pabinger I, Fries D, Schöchl $H$, et al. Tranexamic acid for treatment and prophylaxis of bleeding and hyperfibrinolysis. Wien Klin Wochenschr. 2017; 129(9-10): 303-316, doi: 10.1007/s00508-017-1194-y, indexed in Pubmed: 28432428.

32. Pilbrant A, Schannong M, Vessman J, et al. Pharmacokinetics of tranexamic acid after intravenous administration to normal volunteers. Eur J Clin Pharmacol. 1974; 7(5): 375-380, doi: 10.1007/BF00558210, indexed in Pubmed: 4422030.

33. Box HN, Tisano BS, Khazzam M. Tranexamic acid administration for anatomic and reverse total shoulder arthroplasty: a systematic review and meta-analysis. JSES Open Access. 2018; 2(1): 28-33, doi: 10.1016/j.jses.2017.12.004, indexed in Pubmed: 30675564.

34. Hartland AW, Teoh KH, Rashid MS. Clinical Effectiveness of Intraoperative Tranexamic Acid Use in Shoulder Surgery: A Systematic Review and Meta-analysis. Am J Sports Med. 2021 [Epub ahead of print]: 
363546520981679, doi: 10.1177/0363546520981679, indexed in Pubmed: 33475421.

35. Roberts I, Shakur H, Coats T, et al. The CRASH-2 trial: a randomised controlled trial and economic evaluation of the effects of tranexamic acid on death, vascular occlusive events and transfusion requirement in bleeding trauma patients. Health Technol Assess. 2013; 17(10): 1-79, doi: 10.3310/hta17100, indexed in Pubmed: 23477634.

36. Morte D, Lammers D, Bingham J, et al. Tranexamic acid administration following head trauma in a combat setting: Does tranexamic acid result in improved neurologic outcomes? J Trauma Acute Care Surg. 2019; 87(1): 125-129, doi: 10.1097/TA.0000000000002269, indexed in Pubmed: 30908452.

37. Montgomery HR, Drew B. Tactical Combat Casualty Care (TCCC) Update. JSpec Oper Med. 2020; 20(2): 152-153, indexed in Pubmed: 32573756.

38. Bennett BL, Butler FK, Wedmore IS. Tactical Combat Casualty Care: Transitioning Battlefield Lessons Learned to Other Austere Environments. Wilderness Environ Med. 2017; 28(2S): S3-S4, doi: 10.1016/j. wem.2017.01.003, indexed in Pubmed: 28284484. 